\title{
Erratum to: Biomass, basic density and biomass expansion factor functions for European beech (Fagus sylvatica L.) in Denmark
}

\author{
Jens Peter Skovsgaard • Thomas Nord-Larsen
}

Published online: 30 May 2012

(c) Springer-Verlag 2012

Erratum to: Eur J Forest Res (2012) 131:1035-1053

DOI 10.1007/s10342-011-0575-4

There were two serious omissions in the original publication. The two sentences mentioned below are critical for the understanding and use of our results.

Page 1043, subsection Biomass, right column, paragraph below Eq. 1: At the end of the paragraph, the following sentence should be added: "Biomass is predicted in units of $\mathrm{kg}$ ".

Page 1044, subsection Basic density, left column, paragraph below Eq. 2: Before the last sentence of the paragraph, the following sentence should be inserted: "Basic density is predicted in units of $\mathrm{kg} \mathrm{m}^{-3}$ ".

The online version of the original article can be found under doi:10.1007/s10342-011-0575-4.

J. P. Skovsgaard ( $\square)$

Southern Swedish Forest Research Centre, Swedish University

of Agricultural Sciences, 23053 Alnarp, Sweden

e-mail: jps@slu.se

T. Nord-Larsen

University of Copenhagen, Forest \& Landscape,

23 Rolighedsvej, 1958 Frederiksberg C, Denmark 